will be of interest mainly to those concerned with the planning of health care for large populations, both for its methodology and for its detailed consideration of many internationally important factors in such planning.

RICHARD KEATINGE, Registrar in Community Medicine, Department of Community Medicine, Wandsworth Health Authority, London

\section{Psychology, Ethics and Change}

Edited by Susan Fairbairn and Gavin Fairbairn, 284 pages, London, £9.95, Routledge \& Kegan Paul, 1987

This book provides a welcome contribution to the examination of the moral values that underlie attempts to bring about psychological change. The editors see the book as an introduction leading to further debate about ethical issues. It is a multi-author volume, and the separate contributions deal with diverse issues. As such, it does not attempt to provide a coherent analysis or answers to questions, but allows each author to present his or her own preoccupations. Examples of some of the issues covered are: the appropriateness of a scientific basis for psychological theories; ethical concerns of different models of therapy; appropriate goals of therapy; behavioural medicine, and a challenge to psychologists to face their responsibilities in the face of nuclear threat.

Different preoccupations lead sometimes to mutually exclusive conclusions. One contributor argues for the provision of psychotherapy for everyone, whereas others consider the possibility of a 'disabling' effect of psychotherapy, when experts take over roles formerly performed by people themselves or by family and friends. There are arguments, wearyingly familiar to psychologists, from contributors who present their own theoretical model as the only ethical one. Some abuse is hurled at behaviour therapy and at family therapy. Practitioners in these two therapies, perhaps the most overtly manipulative, have for a long time grappled with ethical considerations relating to their practices. It is sometimes those whose control is more covert who may be much more complacent.

The chapters which have most relevance to medical ethics are those to do with psychological contributions to physical well-being. There is an excellent review by Rob Sanson-Fisher and Deborah Turnbull of the ethical issues involved in attempts to change the lifestyle of the community. They look at the ethics of health education and point out that giving information without providing the skills needed to change behaviour deprives a person of true autonomy to choose good health practices. They also point out the dangers of disregarding social contexts and working conditions in promoting individual responsibility for health. Also of interest are the issues involved in training medical students to be more effective communicators and considerations of autonomy and power in the doctor-patient relationship. There is a chapter by Annabel Broome on the benefits of psychological intervention in medical settings, and Richard Lindley questions the fairness in the distribution of health care and argues for psychotherapy being considered essential care.

A chapter on the ethical issues of psychotherapy for women, by Sue Llewelyn, concentrates on unethical behaviour which is especially important in relation to women, especially when the therapist is male. The occurrence of sexual abuse within the therapeutic relationship is examined as well as stereotyped attitudes towards women which may not be in their best interests. The author reminds us that all professionals who treat women with mental health problems need to consider what it is in the social context of women's lives that makes them disproportionately susceptible to mental health problems and to question whether the professional relationship doesn't reproduce some of these problems.

This book brings together people with a variety of viewpoints from within philosophy, psychology, psychotherapy and behavioural medicine. It provides some very lively and challenging reading and should be interesting to all those who are concerned with the moral dilemmas in psychological practice and also with the relationship between psychology and medicine. I would have liked to see some discussion of the ethical issues related to mental health and people from ethnic minorities but the book is a very stimulating introduction to a debate that has been surprisingly neglected in clinical psychology.

LORETTA SHOBEN, Principal Clinical Psychologist,
Psychology Department, Claybury Hospital, Woodford Green, Essex

\section{Pastoral Care and Ethical Issues In and Out of Work: A Pastoral Perspective}

Paul H Ballard, 192 pages, Edinburgh, £4.95, St Andrew Press, 1987

Paul Ballard trained for the Baptist ministry. His approach to work and employment as a pastoral concern is both sociological and theological. Indeed his book is one of large scope, even if it does not aspire to deal in any great depth with the variety of subjects it covers.

Ballard throws light on the recent history of employment in this country through many references to both Catholic and Protestant ethics and theologies of work. He also refers to modern political ideologies and economic theories.

Writing about the present, Ballard describes the trauma of losing one's job and unemployment. He analyses the degree of responsibility, engagement, work satisfaction and conflict entailed by different kinds of work. He examines the roles in society of both those who work and those who are unemployed. And he does so from the point of view of both the particular individual and those around him.

Viewing the pastoral care of both unemployed and employed against this wide background, the author takes the role of the counsellor to be largely educational. He does not see it solely as ministering to those in crisis but, instead more widely, as teaching people to make their own informed choices and to respond rationally and knowledgeably to their situations.

This book is both analytic and descriptive. It contains a detailed bibliography and, at the end of each chapter, a list of topics for discussion. It should provide stimulating reading for counsellor and counselled alike.

AGNETA SUTTON, The Linacre Centre, 60 Grove End Road, London NW8 9NH 